УДК 398.22

ББК $82.3(=66 \mathrm{I})$

РЕЦЕНЗИЯ НА ИЗДАНИЕ:

САМПО. РУНЫ ПОХЬЁЛЫ: (КАРЕЛЬСКИЙ ЭПОС) / СОСТ. И ОБР.: Д. БАКУЛИН; РУС. ПЕР.: А. БАКУЛИН. СПб.: ЛЕМА, 2018.383 с.

(C) 2019 г. М.В. Кундозерова, В.П. Миронова Институт языка, литературы и истории КарНЦ РАН - обособленное подразделение Федерального государственного бюджетного учреждения науки Федерального исследовательского центра «Карельский научный центр Российской академии наук», Петрозаводск, Россия

Дата поступления статьи: І2 апреля 2019 г. Дата публикации: 25 сентября 2019 г.

DOI: IO.22455/2500-4247-2019-4-3-398-407

Аннотация: В статье рецензируется книга Д.А. и А.А. Бакулиных, состоящая из поэмы «Сампо. Руны Похьёлы», которая преподносится авторами как первый карельский народный эпос, и предисловия к ней. Рассматриваются национальный фон и предыстория появления поэмы, некоторые сюжеты и мотивы, а также язык произведения. Особое внимание уделено анализу отдельных положений предисловия. В целом, представленная поэма является не народным эпосом, а новым литературным произведением, созданным на основе выборочных карельских рун.

Ключевые слова: народный эпос, мифология, Калевала, карельский язык, Лённрот, поэма, сампо, Похьёла.

Информация об авторе: Мария Владимировна Кундозерова — кандидат филологических наук, младший научный сотрудник, Институт языка, литературы и истории КарНЦ РАН - обособленное подразделение Федерального государственного бюджетного учреждения науки Федерального исследовательского центра «Карельский научный центр Российской академии наук», ул. Пушкинская, д. II, I859Iо г. Петрозаводск, Республика Карелия, Россия. ORCID ID: о0о०-о0оI-5423-8709

E-mail: maria.vlasova@mail.ru

Валентина Петровна Миронова - кандидат филологических наук, старший научный сотрудник, Институт языка, литературы и истории КарНЦ РАН - обособленное подразделение Федерального государственного бюджетного учреждения науки Федерального исследовательского центра «Карельский научный центр Российской академии наук», ул. Пушкинская, д. II, I859Iо г. Петрозаводск, Республика Карелия, Россия. ORCID ID: оooo-oooI-63IO-556I

E-mail: tutkija@mail.ru

Для цитирования: Кундозерова М.В., Миронова В.П. Рецензия на издание: Сампо. Руны Похьёлы: (карельский эпос) / сост. и обр.: Д. Бакулин; рус. пер.: А. Бакулин. СПб.: Лема, 2018. 383 с. // Studia Litterarum. 2019. Т. 4, № 3. С. 398-407.

DOI: $10.22455 / 2500-4247-2019-4-3-398-407$ 


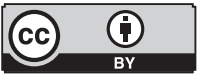

This is an open access article distributed under the Creative Commons Attribution 4.0 International (CC BY 4.0)

\title{
REVIEW OF SAMPO. RUNES OF POHJOLA (KARELIAN EPIC); ED. BY D. BAKULIN; TRANSL. BY A. BAKULIN
}

\author{
(C) 20I9. M.V. Kundozerova, V.P. Mironova \\ Institute of Linguistics, Literature and History \\ of the Karelian Research Centre, Russian Academy \\ of Sciences, \\ Petrozavodsk, Russia \\ Received: April I2, 2019 \\ Date of publication: September 25, 2019
}

\begin{abstract}
The article reviews the publication of the poem Sampo. The Runes of Pohjola by D.A. and A.A. Bakulins presented by the authors as the first Karelian national epic. It examines the national background and the history of the poem's creation, its plots and motifs as well as its language. The review particularly focuses on the Introduction and its main considerations. Reviewers argue that the poem is not a national epic but a new literary work created on the basis of selective Karelian runes.
\end{abstract}

Keywords: epic, mythology, Kalevala, Karelian language, Lönnrot, poem, sampo, Pohjola.

Information about the author: Maria V. Kundozerova, $\mathrm{PhD}$ in Philology, Institute of Linguistics, Literature and History of Karelian Research Centre, Russian Academy of Sciences, Pushkinskaya II, I859Io Petrozavodsk, Russia. ORCID ID: oooo-oooI5423-8709

E-mail: maria.vlasova@mail.ru

Valentina P. Mironova, PhD in Philology, Institute of Linguistics, Literature and History of Karelian Research Centre, Russian Academy of Sciences, Pushkinskaya II, I859IO Petrozavodsk, Russia. ORCID ID: 0000-000I-63IO-556I

E-mail: tutkija@mail.ru

For citation: Kundozerova M.V., Mironova V.P. Review of Sampo. Runes of Pohjola (Karelian Epic); ed. by D. Bakulin, transl. by A. Bakulin. Studia Litterarum, 2019, vol. 4, no 3, pp. 398-407. (In Russ.) DOI: IO.22455/2500-4247-20I9-4-3-398-407 
На сегодняшний день в среде исследователей карельского фольклора общеизвестным фактом является то, что в народной традиции карелов единого эпоса, скрепленного общей сюжетной линией, не существовало. Однако широкое бытование получили различные по времени своего возникновения эпические руны, сюжеты которых объединялись в некие тематические циклы (например, цикл рун о сампо). На основе рун, собранных в XIX в. на территории российской и финляндской Карелии, а также Ингерманландии, Элиасом Лённротом была написана эпическая поэма «Калевала» [4], первое издание которой вышло в г835 г., а второе, дополненное самим же автором, — в І849 г. Произведение получило широкую известность и было переведено на различные языки мира. Эпическая поэма Лённрота послужила толчком к росту национального самосознания финнов, к развитию литературного финского языка. «Калевала» является национальным достоянием по обе стороны российско-финляндской границы. При этом в Финляндии поэма воспринимается как национальный финский эпос, в России же ее называют карело-финским народным эпосом, чем подчеркивается вклад обоих народов в появление «Калевалы».

Спустя почти полтора столетия после выхода в свет поэмы Лённрота, в последней четверти XX в., идеей создания национальных литературных эпосов были воодушевлены деятели культуры и науки практически всех финно-угорских республик. Так, в І986 г. М.Г. Худяковым был создан удмуртский героический эпос «Дорвыжы» [3]. Несколькими годами позже, в 1993 г., К.Ф. Жаков подготовил коми литературный эпос «Биармия» [I]. В 1999 г. увидел свет марийский героический эпос «Югорно» [II], автором которого стал А.Я. Спиридонов. Причем удмуртский и марийский эпосы первоначально были написаны на русском языке, а только потом были пе- 
реведены на удмуртский и марийский соответственно. Тогда же, в г990-е гг. увидел свет литературный вариант эрзянско-мокшанского героического эпоса А.М. Шаронова «Масторава» [7].

В Карелии и Финляндии этот процесс начался несколько позже. В 2012 г. в Петрозаводске Н.Г. Зайцевой был создан вепсский эпос «Вирантаназ», во многом опирающийся на сюжеты вепсского фольклора [2]. B 20I4 г. в Финляндии был опубликован ингерманландский эпос «Liekku» («Колыбель»), подготовленный М. Кемппинен на основе ингерманландских лирических песен [I5]. Все перечисленные работы созданы на основе фольклора того или иного народа и являются авторскими произведениями.

В этом же ряду стоит и поэма братьев Д.А., А.А. Бакулиных «Сампо. Руны Похьёлы» [го], увидевшая свет в конце 2018 г. в Санкт-Петербурге. Авторы позиционируют свое произведение как первый народный эпос на карельском языке, а в качестве основной идеи своей работы считают знакомство читателей с подлинными эпическими рунами в противовес поэме Лённрота «Калевала», которая, хотя и считается карело-финским народным эпосом, является, по сути, литературным памятником на финском языке.

Произведение «Сампо. Руны Похьёлы» состоит из предисловия и текста поэмы, которая включает 8 глав и заключение, так или иначе опирающиеся на сюжеты и мотивы, бытовавшие в Беломорской Карелии. По признанию самих же авторов, источниками для их варианта эпоса послужили аутентичные эпические песни, опубликованные в первом томе «Древних рун финского народа» [I7], а также в сборнике «Рода нашего напевы. Избранные песни рунопевческого рода Перттуненов» [9]. Ключевыми, равно как и в лённротовской поэме «Калевала», являются темы сотворения мира, сватовства и поисков жены, а объединяющим - сюжет о создании и похищении сампо. Однако предложенная сюжетная коллизия в поэме Бакулиных имеет довольно неожиданные повороты. Например, хозяйка Похьёлы Лоухи оказывается юной девой, которая выходит замуж за Лемминкяйни (он же и Ёукахайни). По дороге домой выясняется, что они - дети одной матери, двойняшки, разлученные в детстве. Осознав факт инцеста, Лемминкяйни бросает свою новоиспеченную жену в поле и спешит обратно в Похьёлу, чтобы украсть сампо. Затем, раскрутив крышку сампо, Лемминкяйни засыпает вечным сном. Однако перед этим он еще убивает Вяйнямёйни - срубает у него голову с плеч, «как ботву с репы». Подобные повороты сюжета 
не только непривычны для тех, кто знаком с текстом «Калевалы», но они также не имеют ничего общего с народной традицией. Схожих сюжетов и мотивов нет не только в текстах, записанных в Беломорской, но и во всей Карелии. Ни один рунопевец не пел о том, что Лемминкяйни/Лемминкяйнен (ставший вдруг и Ёукахайни/Ёукахайненом) был братом-близнецом и мужем хозяйки Похьёлы. Подобная сюжетная линия никак не может называться карельской. Тем более что сами авторы в предисловии отмечают, что для описания жизненного пути Лемминкяйни они опираются на «древнеегипетский миф о боге умирающей и воскресающей природы Осирисе, брате и супруге Исиды» [г, с. 32].

Появление новых персонажей (например, герой, который носит два имени - Лемминкяйни и Ёукахайни) также является плодом фантазии авторов. В народных рунах эти имена носят разные герои, выступающие в совершенно разных сюжетах с отличными функциями. Отметим попутно, что и Лённрот в некоторых случаях при написании своей поэмы придумывал собирательные образы на основе нескольких, бытовавших в народной традиции, или же давал имена безымянным героям карельских эпических рун. К примеру, в народных вариантах сестра Лемминкяйнена не имеет имени, тогда как в «Калевале» ее называют Айникки. Сестра Ёукахайнена также получает имя Айно, которое Лённрот образовал от прилагательного аinoa («единственная»), ставшее впоследствии постоянным эпитетом, характеризующим девушек в эпической поэзии: Anni neitto, aino neitto («Анни девушка, единственная девушка»). Вполне очевидно, что и в рассматриваемом произведении, и в «Калевале» мы имеем дело с явлением одного порядка - создание новых персонажей и новых имен, что характерно для литературного произведения в целом.

Авторы, как нам кажется, взяли на себя огромную смелость заниматься реконструкцией древних мифологических источников и мотивов, не будучи исследователями в данной области. Произвольно обращаясь с исходным материалом, интерпретируя его по-своему, они допустили в тексте неточности и даже грубейшие ошибки. В результате, несомненно, перед нами новое литературное произведение, которое нельзя назвать карельским народным эпосом, как указано на титульном листе. Причем надписи титульного листа на карельском и русском языке не совпадают (сравни: карельский эпос и karjalaini kanšaneepossa - букв. «карельский народный эпос»). Похоже, в том, что это народный эпос, авторы хотят убедить лишь карелоязычную публику. 
Следует несколько слов сказать и о стиле произведения. Знатокам карельской эпической поэзии не составляет никакого труда выявить оригинальные фрагменты, заимствованные из рун, и строки, написанные самими авторами, содержащие к тому же большое количество грамматических ошибок. В тексте не всегда соблюдается ритмика, нарушается калевальский размер, выбор лексики вызывает большие сомнения.

Отдельно хочется сказать о предисловии. На первый взгляд, авторы уделили в нем внимание многим моментам: написано о бытовании эпосов в рамках мировой культуры в целом и о карельских эпических рунах в частности, очерчены основные этапы собирания карельских рун и указаны собиратели, сказано о бытовании сюжетов и т. д. Однако многие высказанные положения ошибочны, ничем не аргументированы, не подкреплены ссылками на работы предшественников, что доказывает некомпетентность авторов в рассматриваемых вопросах.

Не совсем корректно, а порой и просто уничижительно описан вклад Элиаса Лённрота как собирателя карельских рун и создателя поэмы «Калевала». Грамматические и фонетические неточности его полевых записей, на которые с критикой обрушиваются авторы, обусловлены в первую очередь тем, что Лённрот ставил перед собой совершенно иную задачу, а именно сбор сюжетного материала. Необходимо было бы подчеркнуть огромную работоспособность Лённрота и тот огромный вклад, который он сделал в деле собирания и сохранения карельского фольклорного наследия.

Абсурдной выглядит и попытка политизировать саму идею создания эпоса «Калевала» и принижение роли Лённрота в этом вопросе. В научном мире существует большое количество литературы о его жизни и творчестве [5, І3], о процессе создания «Калевалы» [6; 14], изданы путевые дневники и письма Лённрота [8], и каждый знакомый с ними читатель знает о том долгом пути, который прошел автор от идеи создания эпоса до его воплощения. Отведение Лённроту роли некоего бедного, неродовитого простачка, который не подходит на роль «уважаемого ученого мужа, независимо мыслящего и финансово самостоятельного, способного позабыть о социальном заказе и пренебречь политической целесообразностью» и которому сверху было спущено указание написать эпос «Калевала» [Іо, с. 22], служит индикатором невежества авторов рассматриваемого издания. Создание эпоса «Калевала» было титаническим трудом Лённрота, который, имея сотни ва- 
риантов рун, разработал некую единую сюжетную линию, придумал связки, новые мотивы и т. д. Вопросы создания эпоса были рассмотрены в монографии Э.С. Киуру и А.И. Мишина «Фольклорные истоки “Калевалы” [6], которая также не указана в списке литературы. Данной проблематике посвящены и многие другие исследовательские работы.

Непростительным является и то, что авторы заведомо скрывают от читателя существование литературного эпоса на карельском языке. В 2009 г. вышел перевод «Калевалы» на ливвиковское наречие карельского языка, выполненный карельской писательницей 3.Т. Дубининой [І6]. В 20I5 г. свет увидел перевод на собственно карельское наречие карельского языка, автором которого выступила исследователь фольклора, носитель севернокарельской традиции Р.П. Ремшуева [г2]. Авторы не только умалчивают об этих переводах, они еще и публично (на презентации ${ }^{\mathrm{I}}$ ) умаляют важность этих трудов, называя перевод рун «Калевалы» на карельский язык «никому не нужной работой». Замалчивание фактов уже дает свои отрицательные результаты: карельские СМИ подают новость о выходе в свет книги Бакулиных не иначе как публикацию рун карело-финского эпоса «Калевала», переведенных на карельский язык. Вполне очевидно, что возникла ситуация, при которой не совсем ясно, чем же является произведение Бакулиных: народным эпосом, сборником рун или поэмой? Чем оно отличается от «Калевалы» и как связано с карельским языком?

В этой связи хочется обратить внимание на следующие важные моменты: поэма Лённрота «Калевала», не являющаяся подлинно народным эпосом, была переведена с финского языка на собственно карельское наречие карельского языка в 20I5 г. Поэма братьев Бакулиных, также не являющаяся подлинно народным эпосом, написана на собственно карельском наречии карельского языка.

При этом язык поэмы Бакулиных оставляет желать лучшего. Как отмечает автор предисловия, языком произведения является «собственно карельское наречие», и авторы поэмы «старались вернуть стихам их первоначальное, карельское звучание, придерживаясь при написании норм современной карельской письменности» [Іо, с. 38]. Отсюда неизбежно следует два вопроса: г) откуда авторы могут знать, как первоначально звучали

I П Презентация книги Дмитрия и Алексея Бакулиных «Сампо. Руны Похьёлы» состоялась 30 января 2ог9 г. в Национальной библиотеке Республики Карелия. 
руны? и 2) каких именно норм карельской письменности придерживались авторы? На эти вопросы, к сожалению, предисловие ответов не дает.

Братья Бакулины, по их собственному признанию, не являются знатоками карельского языка, специалисты по карельскому языку ими для работы над поэмой не привлекались. Карельские тексты не вычитывались, переводы не проверялись. Всё это стало причиной множественных недочетов разного характера, выявляющихся при чтении. Это и отсутствие качественного чередования согласных (lietokši, tähtet [ı, с. 326], paissamaha [ıо, с. 352]), несогласованность числа подлежащего и сказуемого (tuli čuarit [Iо, c. 326]), определения и определяемого (vanhojen vaimon miärihi [Іо, c. 332]), неправильные падежные формы дополнения (valiče parahan šulhon, kačo kaunehemman miehen [Iо, c. 328], löyvän Lieton Lemminkäistä, järetöintä Joukahaista [ıо, c. 350]; löyti lemmen lehti [ıо, c. 360]; kantaja šai kakšosien [ıо, c. 342]), неверное склонение глаголов (šynnin [Іо, c. 328]), ошибки в гармонии гласных (pakkopäivissaha [ıо, c. 342], ihmisilla [ıо, c. 372], kinterešša [ıо, c. 44]) и проч.

Использование диакритического знака (указывающего на одну из главных фонетических особенностей собственно карельского наречия) не всегда является корректным: в некоторых случаях он отсутствует (vaimoksie [ıо, с. 326], jossa, varsin [Iо, c. 334], lausu, kiusattuna [1о, с. 362], täysi, tusissaha [Iо, c. 342], tähystämäššä [Іо, c. 58]), в некоторых — является излишним (tallišša [ıо, c. 342], poikuaši, itkuvirttäši [ıо, c. 348]). Примечательно, что авторы пренебрегли использованием диакритического знака при написании названия самого главного артефакта поэмы - сампо (sampo [Іо, с. 46 и др.]). А ведь именно благодаря точной фонетической записи рун финского собирателя А. Борениуса, известно, что на севере Карелии рунопевцы пели о шампо (公атро [I7, c. 85]).

Грамматические ошибки (šuurimmien kylien, šuurimmat kylät runonlaulajien) содержит и самый первый разворот книги с картой, на которой, в свою очередь, недостоверно указано распространение эпической традиции. Это еще раз демонстрирует, насколько авторы далеки от карельской культуры, языка и фольклора.

В заключение отметим, что Э. Лённрот при создании своей поэмы имел столько фольклорного материала, которого, по его личному признанию, хватило бы на составление семи совершенно разных «Калевал». И поэма братьев Бакулиных - лишь одна из таких возможных авторских 
версий, а не первый карельский народный эпос. Это новое литературное произведение, созданное на основе карельских рун, которое, на наш взгляд, находится еще дальше от народной поэзии, чем «Калевала».

\section{Список литературы}

I Биармия: коми литературный эпос / К.Ф. Жаков. Сыктывкар: Союз писателей Республики Коми, 2013. 350 с.

2 Вирантаназ: поэтический эпос на вепсском, финском, эстонском и русском языках / Н.Г. Зайцева; пер. М. Ниеминен, Я. Ыйспуу, В.А. Агапитов. Петрозаводск: Периодика, 2016. 213 с.

3 Дорвыжы: удмуртский героический эпос / М. Худяков; ред. Д.А. Яшина, В.М. Ванюшева. Ижевск: Удмуртия, 2008. І37 с.

4 Калевала: эпическая поэма на основе древних карельских и финских народных песен / Э. Лённрот; пер. Э. Киуру, А. Мишин. Петрозаводск: Карелия, г998. 583 с.

5 Карху Э.Г. Элиас Лённрот: жизнь и творчество. Петрозаводск: Карелия, 1996. $235 \mathrm{c}$.

6 Киуру Э.С., Мишин А.И. Фольклорные истоки «Калевалы». Петрозаводск: Изд-во ПетрГУ, 200I. 248 с.

7 Масторава / А.М. Шаронов. Саранск: Эрзянь Мастор, 2ого. 263 с.

8 Путешествия Элиаса Лённрота: Путевые заметки, дневники, письма I828-І842 гг. / Э. Лённрот; пер. В.И. Кийранен и Р.П. Ремшуевой. Петрозаводск: Карелия, г985. 320 с.

9 Рода нашего напевы: Избранные песни рунопевческого рода Перттуненов / сост. Э.С. Киуру, Н.А. Лавонен. Петрозаводск: Карелия, г985. 272 с.

Iо Сампо. Руны Похьёлы: (карельский эпос) / сост. и обр. Д. Бакулина; рус. пер. А. Бакулина. СПб.: Лема, 2018, 383 с.

II Югорно: песнь о вещем пути: эпос мари / А. Спиридонов; пер. с русского А.И. Мокеева. 2-е изд. Йошкар-Ола: Марийское книжное изд-во, 20I4. 245 с.

I2 Kal'evala: vienankarjalakši / Elias Lönnrot; kiäntäjä Raisa Remšujeva; kuv. Vitali Dobrinin. Helsinki: Karjalan Šivissyššeura, 20I5. 526 s.

I3 Kaukonen V. Lönnrot ja Kalevala. Helsinki: Suomalaisen Kirjallisuuden Seuran toimituksia, I979. I98 s.

I4 Kaukonen V. Lönnrotin Kalevalan toinen painos. Helsinki: Suomalaisen Kirjallisuuden Seuran toimituksia, I956. $635 \mathrm{~s}$.

I5 Liekku: Inkerin eepos / laat. Mirja Kemppinen. Kuhmo: Juminkeko, 2013. 9I s.

I6 Lönnrot E. Kalevala: karjalankieline Kalevala-eepossu / Elias Lönnrot; kiänd. Zinaida Dubinina. Helsinki: Karjalan Kielen Seura, 2009. 5 I9 s.

I7 Suomen kansan vanhat runot. I. Helsinki: Suomalaisen Kirjallisuuden Seuran toimituksia, I908. 92I s. 


\section{References}

I Biarmiia: komi literaturnyi epos [Biarmiya: Komi literary epic], K.F. Zhakov. Syktyvkar, Soiuz pisatelei Respubliki Komi Publ., 20I3. 350 p. (In Russ.)

2 Virantanaz: poeticheskii epos na vepsskom, finskom, estonskom i russkom iazykakh [Virantanaz: poetic epic in Vepsian, Finnish, Estonian, and Russian], N.G. Zaitseva; transl. by M. Nieminen, Ia. Yispuu, V.A. Agapitov. Petrozavodsk, Periodika Publ., 2016. 2I3 p. (In Russ.)

3 Dorvyzhy: udmurtskii geroicheskii epos [Dorvyzhi: Udmurt heroic epic], Mikhail Khudiakov; ed. by D.A. Iashina, V.M. Vaniusheva. Izhevsk, Udmurtiia Publ., 2008. I37 p. (In Russ.)

$4 \quad$ Kalevala: epicheskaia poema na osnove drevnikh karel'skikh i finskikh narodnykh pesen [Kalevala: epic poem based on ancient Karelian and Finnish folk songs], E. Lennrot; transl. by E. Kiuru, A. Mishin. Petrozavodsk, Kareliia Publ., I998. 583 p. (In Russ.)

$5 \quad$ Karkhu E.G. Elias Lennrot: zhizn' i tvorchestvo [Elias Lönnrot: life and work]. Petrozavodsk, Kareliia Publ., I996. 235 p. (In Russ.) Kiuru E.S., Mishin A.I. Fol'klornye istoki “Kalevaly" [Folklore origins of the Kalevala]. Petrozavodsk, Izd-vo PetrGU Publ., 200I. 248 p. (In Russ.) Mastorava [Mastorava], A.M. Sharonov. Saransk, Erzian’ Mastor Publ., 20Io. 263 p. (In Russ.)

8 Puteshestviia Eliasa Lennrota: Putevye zametki, dnevniki, pis'ma I828-I842 gg. [Travels of Elias Lönnrot: Travel notes, journals, letters, I828-I842], E. Lennrot; transl. by V.I. Kiiranen and R.P. Remshueva. Petrozavodsk, Kareliia Publ., I985. 320 p. (In Russ.) Roda nashego napevy: Izbrannye pesni runopevcheskogo roda Perttunenov [The songs of our kin. Selected songs of Runo-singing Perttunen kin], comp. by. E.S. Kiuru, N.A. Lavonen. Petrozavodsk, Kareliia Publ., I985. 272 p. (In Russ.) Sampo. Runy Pokh'ely: (karel'skii epos) [Sampo. The runes of Pohjola: (Karelian epic)], comp by D. Bakulina; Russian transl. by A. Bakulina. St. Petersburg, Lema Publ., 2018. 383 p. (In Russ.) Iugorno: pesn' o veshchem puti: epic mari [Yugorno: a song about the prophetic path: the mari epic], Anatolii Spiridonov; transl. from Russian by A.I. Mokeev. $2^{\text {nd }}$ ed. IoshkarOla, Mariiskoe knizhnoe izdatel'stvo Publ., 20I4. 245 p. (In Russ.) Kal'evala: vienankarjalakši, Elias Lönnrot; kiäntäjä Raisa Remšujeva; kuv. Vitali Dobrinin. Helsinki, Karjalan Šivissyššeura, 2015. 526 p. (In Karelian) Kaukonen V. Lönnrot ja Kalevala. Helsinki, Suomalaisen Kirjallisuuden Seuran toimituksia, I979. I98 p. (In Finnish)

I4 Kaukonen V. Lönnrotin Kalevalan toinen painos. Helsinki, Suomalaisen Kirjallisuuden Seuran toimituksia, I956. 635 p. (In Finnish)

I5 Liekku: Inkerin eepos, laat. Mirja Kemppinen. Kuhmo, Juminkeko, 20I3. 9I p. (In Finnish)

I6 Lönnrot E. Kalevala: karjalankieline Kalevala-eepossu, Elias Lönnrot; kiänd. Zinaida Dubinina. Helsinki, Karjalan Kielen Seura, 2009. 5I9 p. (In Karelian) Suomen kansan vanhat runot. I. Helsinki, Suomalaisen Kirjallisuuden Seuran toimituksia, I908. 921 p. (In Finnish) 